\title{
Modeling and simulation of forward Al extrusion process using FEM
}

\begin{abstract}
The main objective of this paper is to study the effect of extrusion parameters (extrusion stresses and temperature) and die geometry, i.e. extrusion radius, on the extruded aluminum quality using FEM Simulation Technique. For this purpose, the general FEA Software ABAQUS was used to set up the finite element model of the warm aluminum extrusion in two dimensions (2D). Aluminum alloy Al-2014 was used as billet material, with 40mm diameter and $75 \mathrm{~mm}$ length. The extrusion process was modeled as isothermal, which means that the billet material was preheated at a specific temperature and then pressured into the circular die, with extrusion ratio 3.3. Optimized algorithms for extrusion parameters were proposed regarding the concluded simulating results. The results showed that small die angles required higher extrusion load than large die angles. In all die geometry used, the deformation of aluminum billet, which is caused by shearing and compression stresses, happened in a small sectional area (bearing area). The results also showed that, the values of these stresses can increase or decrease depending on the die entrance angle and the die bearing length. To avoid the effects of these stresses on die dimensions; the hardness, material selection, and geometry should be well calculated. An axis-symmetrical 2D geometric model of the tooling and billet was constructed for the analysis. Data obtained from the FE model included diework piece contact pressure, effective stress and strain and material deformation velocity. The correlation between the calculated and FEA data was obtained in this research.
\end{abstract}

Keyword: Aluminum alloys; Billet; Die; Extrusion; FEM; Stress analysis 